\title{
Article \\ The Utilization of Phosphogypsum as a Sustainable Phosphate-Based Fertilizer by Aspergillus niger
}

\author{
Da Tian $1,2,3, *,+\left(\mathbb{D}\right.$, Jingjing Xia ${ }^{1,2,3,+}$, Ningning Zhou ${ }^{1,2,3}$, Meiyue Xu ${ }^{1,2,3}$, Xiang Li ${ }^{1,2,3}$, Liangliang Zhang ${ }^{1,2,3}$, \\ Shuhua $\mathrm{Du}^{4}$ and Hongjian Gao ${ }^{1,2,3, *}$
}

1 Anhui Province Key Laboratory of Farmland Ecological Conservation and Pollution Prevention, College of Resources and Environment, Anhui Agricultural University, Hefei 230036, China; 19116102@stu.ahau.edu.cn (J.X.); 19116099@stu.ahau.edu.cn (N.Z.); 19116105@stu.ahau.edu.cn (M.X.); 869684757@stu.ahau.edu.cn (X.L.); zhangliangliang@ahau.edu.cn (L.Z.)

2 Key Laboratory of JiangHuai Arable Land Resources Protection and Eco-Restoration, Ministry of Natural Resources P.R.C., Anhui Agricultural University, Hefei 230036, China

3 Research Centre of Phosphorus Efficient Utilization and Water Environment Protection along the Yangtze River Economic Belt, Anhui Agricultural University, Hefei 230036, China

4 Anhui Provincial Institute of Geological Experiment, Hefei Mineral Resources Supervision and Testing Center, The Ministry of Land and Resources P.R.C., Hefei 230036, China; dushuhua35@163.com

* Correspondence: tianda@ahau.edu.cn (D.T.); hjgao@ahau.edu.cn (H.G.)

$\dagger$ These authors contributed equally to this work.

check for updates

Citation: Tian, D.; Xia, J.; Zhou, N.; Xu, M.; Li, X.; Zhang, L.; Du, S.; Gao, $\mathrm{H}$. The Utilization of Phosphogypsum as a Sustainable Phosphate-Based Fertilizer by Aspergillus niger. Agronomy 2022, 12, 646. https:// doi.org/10.3390/agronomy12030646

Academic Editor: Claudio Ciavatta

Received: 27 January 2022

Accepted: 3 March 2022

Published: 6 March 2022

Publisher's Note: MDPI stays neutral with regard to jurisdictional claims in published maps and institutional affiliations.

Copyright: (C) 2022 by the authors. Licensee MDPI, Basel, Switzerland. This article is an open access article distributed under the terms and conditions of the Creative Commons Attribution (CC BY) license (https:// creativecommons.org/licenses/by/ $4.0 /)$.

\begin{abstract}
Phosphogypsum (PG) is a by-product of the phosphorus (P) chemical industry, and usually contains $\sim 2 \%$ residual phosphate. The P in PG would cause P pollution in the environment by the way of long-term stacking. Phosphate-solubilizing fungi (PSF) can effectively promote the release of $\mathrm{P}$ from insoluble phosphate. The aim of this study was to investigate the $\mathrm{P}$ release capacity between tricalcium phosphate (TCP) and PG by Aspergillus niger (ANG) via flask experiment. At the same time, the application of PG fertilizer (PGF) in soil was also performed. The dry biomass of ANG between TCP and PG treatment reached the maximum value of 0.71 and $0.38 \mathrm{~g}$, respectively, after five days of incubation. The maximum P concentrations released from PG and TCP by ANG is five and seven days, i.e., 128 and $1103 \mathrm{mg} / \mathrm{L}$, respectively. PG has a similar P release ratio compared with TCP by ANG, i.e., $52 \%$ vs. $55 \%$. In the soil incubation experiment, PGF can significantly increase the soil available P content and continuously maintain the high concentration $(17.2 \mathrm{mg} / \mathrm{kg})$ after four weeks of incubation. The utilization of PG by ANG via the PGF is a feasible pathway to increase the soil $\mathrm{P}$ content, especially for the sustainable use of phosphate resources.
\end{abstract}

Keywords: phosphogypsum; phosphoric fertilization; tricalcium phosphate; Aspergillus niger; phosphate wastes reuse

\section{Introduction}

Phosphate ore (PO) is the primary resource for the production of phosphoric acid, pesticides, and other phosphorus-related chemicals [1-3]. PO is critical to producing chemical phosphate fertilizer (CPF), especially in agricultural production [4]. The supply of $\mathrm{CPF}$ can provide phosphorus $(\mathrm{P})$ for crop growth, which is important for food security and human development [4]. Every year, more than a million tons of PO is consumed in the effort of CPF production [5]. However, as a non-renewable resource, the huge consumption of PO would deplete current global reserves in the future [6].

Phosphogypsum (PG) is a by-product of CPF production via the wet-process phosphoric acid technology [7]. The current global production of PG is estimated to be 100 280 Mt per year [8]. PG is usually acidic ( $\mathrm{pH}$ value 2-4) and could contain toxic elements (heavy metal cations, fluorine, etc.), which are hardly reused (less than 40\%) [9]. Commonly PG is treated as a solid waste by way of land stockpiling $[9,10]$. However, the P in PG can 
be useful for crops [11]. The reuse of PG as a phosphate fertilizer can slow down the exploitation of $\mathrm{PO}$ with positive benefits for the environment $[12,13]$. The content of total $\mathrm{P}$ in PG is about 2.5-7.5\% [14]. Besides soluble P and co-crystallized P, there is also insoluble $\mathrm{P}(\mathrm{IP})$ in PG due to the incompletely decomposed PO [15]. As with geological apatite, the IP in PG also has a low solubility (Ksp $<10^{-70}$ ), which limits the reuse of P in PG [16].

Phosphate-solubilizing fungi (PSF) can secrete large amounts of organic acid and promote the release of $P$ from IP via acidification and chelation $[17,18]$. Compared with phosphate-solubilizing bacteria, the P released from phosphate rocks by PSF is higher than 10 times [19]. Compared with chemical strong acids (e.g., sulfuric acid), the organic acid would be more effective in the release of $P$ from phosphate rocks [20]. For example, oxalic acid has a higher $P$ release ratio compared with sulfuric acid [20]. As a dicarboxylic acid, oxalic acid has the highest acidity constant $\left(\mathrm{p} K_{\mathrm{a} 1}=1.25\right.$ and $\left.\mathrm{p} K_{\mathrm{a} 2}=4.27\right)$, which is effective in $\mathrm{pH}$ reduction and IP dissolution, especially for IP [18,21]. In addition, oxalic acid can also release $\mathrm{P}$ from phosphate rocks by chelating with metal cations, such as $\mathrm{Ca}^{2+}, \mathrm{Al}^{3+}$, $\mathrm{Fe}^{3+}$, etc. $[11,17]$. Therefore, PSF is usually considered as the primary candidate in the dissolution of phosphate rocks [21].

PSF inoculation with phosphate rocks has been applied for the production of phosphatebased bio-fertilizer [22]. In P deficient soil, the inoculation of PSF and phosphate rocks significantly increased the soil soluble $\mathrm{P}$ content and promoted plant growth [23-25]. Oxalic acid secreted by Aspergillus niger dominates the $P$ dissolution process from phosphate rock in soil [23]. However, the secretion of oxalic acid by PSF can be influenced by different environmental factors, such as $\mathrm{pH}$, heavy metal toxicity, IP types, etc. [21,26,27]. For example, the high $\mathrm{Pb}$ concentrations ( $1000 \mathrm{mg} / \mathrm{L}$ ) limit the secretion of oxalic acid by Penicillium oxalicum (P. oxalicum) [28]. Hence, it is necessary to choose a suitable PSF to dissolve IP, especially for PG.

The PSF Aspergillus niger (A. niger) has a strong ability to secrete oxalic acid, even in a considerably stressed environment [28]. In a low $\mathrm{pH}(\sim 2)$ and high $\mathrm{Pb}$ toxicity (500-1500 mg/L) environment, $A$. niger also maintains the high oxalic acid secretion ability $[28,29]$. In addition, $A$. niger can also resist the toxicity of fluorine $(\mathrm{F})(\sim 90 \mathrm{mg} / \mathrm{L})$ and maintain the secretion of oxalic acid [30]. More importantly, the existence of calcium phosphate can also stimulate $A$. niger to secrete more oxalic acid [21]. Therefore, the application of $A$. niger to achieve the reuse of $P$ in PG could be a feasible pathway.

This study aims to investigate the utilization of PG as a phosphate fertilizer with the combination of $A$. niger in a $\mathrm{P}$ deficient soil. The capacity of $\mathrm{P}$ released from tricalcium phosphate (TCP) and PG by A. niger is also investigated. High-performance liquid chromatography (HPLC) was used to analyze the secretion of organic acids. Inductively coupled plasma optical emission spectroscopy (ICP-OES) was used to analyze the release of $\mathrm{P}$ and $\mathrm{Pb}$. Scanning electron microscopy (SEM) and $\mathrm{X}$-ray diffraction (XRD) were used to identify mineral morphology in the process of PG utilization by $A$. niger.

\section{Materials and Methods}

\subsection{Preparation of Fungal Strains}

A. niger (NJDL-12, CGMCC No. 11544) was isolated from the soybean rhizosphere in Nanjing, China. Before incubation, A. niger was inoculated into a potato dextrose agar medium (PDA) in a sterilized environment. After incubating for five days at $28{ }^{\circ} \mathrm{C}$, the formed spores were collected into an Erlenmeyer flask with sterile water and filtered through three layers of sterile gauze to obtain a spore suspension. Then, a hemocytometer was used to measure the concentration of spores to $10^{7} \mathrm{CFU} / \mathrm{mL}$.

\subsection{Medium Preparation}

Pikovskaya (PVK) liquid medium was used in this study to investigate the P-releasing ability of $A$. niger. The PVK medium contained $10 \mathrm{~g}$ glucose, $0.2 \mathrm{~g} \mathrm{NaCl}, 0.25 \mathrm{~g} \mathrm{MgSO}_{4} \cdot 7 \mathrm{H}_{2} \mathrm{O}$, $0.03 \mathrm{~g} \mathrm{FeSO}_{4} \cdot 7 \mathrm{H}_{2} \mathrm{O}, 0.03 \mathrm{~g} \mathrm{MnSO}_{4} \cdot 4 \mathrm{H}_{2} \mathrm{O}, 0.2 \mathrm{~g} \mathrm{KCl}, 0.5 \mathrm{~g}\left(\mathrm{NH}_{4}\right)_{2} \mathrm{SO}_{4}$, and $1 \mathrm{~L}$ deionized water (China National Pharmaceutical Group Chemical Reagent Co., Ltd., Shanghai, China). 
Two phosphates were used as the initial P resources in the PVK medium, i.e., TCP and PG [21].

\subsection{TCP, PG and Soil Collection}

Tricalcium phosphate $\left(\mathrm{Ca}_{3}\left(\mathrm{PO}_{4}\right)_{2}\right)$ was supplied by Shanghai Macklin Biochemical Co., Shanghai, China. PG was collected from the phosphorus chemical industry in Tongling city, Anhui Province, China. The total P content in TCP and PG was $2 \mathrm{~g} / \mathrm{kg} 24.81 \mathrm{mg} / \mathrm{kg}$. The collected PG was air-dried and passed through a 20-mesh sieve. The soil was collected from the North Anhui comprehensive experimental station in Suzhou city, Anhui Province, China. The physical and chemical properties of the soil are shown in Table S3. Before incubation, plant roots and gravel were removed from the soil. All soil samples were ventilated and dried at room temperature, then ground and passed through a 20-mesh sieve. After that, the soil samples were sterilized for $20 \mathrm{~min}$ in a $121^{\circ} \mathrm{C}$ steam sterilization pot.

\subsection{PG Fertilizer Preparation}

The generation of PG fertilizer (PGF) for A. niger was performed by shallow disk fermentation. Before the fermentation, $A$. niger was cultured on potato dextrose agar (PDA) medium for five days at $28{ }^{\circ} \mathrm{C}$ to form spores. Then, the block of $A$. niger containing spores was inoculated to potato dextrose broth (PDB) at $28^{\circ} \mathrm{C}$ and $175 \mathrm{rpm}$ for three days to form a fungal solution. The PGF materials consisted of corn stalk, wheat stalk, PG, rice stalk, soybean powder in a ratio of 8:2:8:1:1. After the sterilization $\left(121^{\circ} \mathrm{C}, 20 \mathrm{~min}\right)$, $2.5 \mathrm{~kg}$ materials and $3.0 \mathrm{~kg}$ fungal solution (ratio 1:1.2) were uniformly mixed by glass rod in a steel pallet. Lastly, the mixture materials were covered with two layers of gauze to continue incubation at $28{ }^{\circ} \mathrm{C}$ for one week, during which the following plot experiment was prepared.

\subsection{Flask Experiment}

The experiment was performed with two treatments, i.e., ANG + TCP $(A$. niger + $\left.\mathrm{Ca}_{3}\left(\mathrm{PO}_{4}\right)_{2}\right)$ and $\mathrm{ANG}+\mathrm{PG}(A$. niger $+\mathrm{PG})$. Before incubation, $100 \mathrm{~mL}$ PVK medium was added into a $250 \mathrm{~mL}$ conical flask and sterilized at $121{ }^{\circ} \mathrm{C}$ for $20 \mathrm{~min}$ [21]. Then, $1.0 \mathrm{~g}$ $\mathrm{Ca}_{3}\left(\mathrm{PO}_{4}\right)_{2}$ was added to one flask and $1.0 \mathrm{~g}$ PG was added to the second flask. Subsequently, $1 \mathrm{~mL}$ of ANG spore suspension was added to each conical flask [21]. Finally, the conical flasks were sealed with a parafilm (BS-QM-003, Biosharp), which contained a $0.22 \mu \mathrm{m}$ air breathable membrane in the middle [21]. All operations were performed under aseptic conditions. After being incubated for three, five, and seven days $\left(28^{\circ} \mathrm{C}, 180 \mathrm{rpm}\right)$, the PVK medium was filtered using a $0.22 \mu \mathrm{m}$ polyethersulfone (PES) membrane [21]. The filtrate was used to determine $\mathrm{pH}$, organic acids, and soluble P. After being dried at $65{ }^{\circ} \mathrm{C}$ for $24 \mathrm{~h}$, the filter was analyzed by XRD and SEM to determine the minerals [21]. The fungi obtained by filtration was dried at $65^{\circ} \mathrm{C}$ for $24 \mathrm{~h}$ to determine biomass and was analyzed by XRD and SEM [21]. All treatments were replicated three times.

\subsection{Soil Incubation Experiment}

There are five treatments in this experiment, i.e., SS (sterilized soil only), SS + ANG (sterilized soil + A. niger), SS + PG (sterilized soil + PG), SS + ANG + PG (sterilized soil + A. niger + PG) and SS + PGF (sterilized soil + PG fertilizer). The soil was sterilized three times at $121^{\circ} \mathrm{C}$ for $20 \mathrm{~min}$ before incubation. In each treatment, $20 \mathrm{~g}$ sterilized soil was added into a $150 \mathrm{~mL}$ white bottle before incubation. The inoculation amount of PG in soil was $1 \mathrm{~g}$, and the amount of PGF was $2 \mathrm{~g}$. Before incubation, the PG and PGF were completely mixed with the soil. The inoculation of $A$. niger was $2 \mathrm{~mL}$. All bottles were incubated in an incubator at $30^{\circ} \mathrm{C}$. After being incubated for one, two, and four weeks, the soil in each treatment was collected and measured for $\mathrm{pH}$ and water-soluble P. In the soil $\mathrm{pH}$ test, the weight ratio of soil and water was 1:2.5. Before the water-soluble P test, $2 \mathrm{~g}$ soil was mixed with $40 \mathrm{~mL}$ deionized water and shaken at $180 \mathrm{rpm}$ and $25^{\circ} \mathrm{C}$ for $18 \mathrm{~h}$. Then, the mixture liquid was centrifuged at $4000 \mathrm{rpm}$ for $10 \mathrm{~min}$ and then stranded for $30 \mathrm{~min}$. 
Finally, the supernatant was filtered via a $0.22 \mu \mathrm{m}$ filter for the water-soluble P test $[23,31]$. The morphology of PGF in soil was also analyzed by SEM. All treatments were replicated three times.

\subsection{Instrumentation}

The $\mathrm{pH}$ value was measured by $\mathrm{pH}$ meter (FE20, Mettler Toledo, Columbus, $\mathrm{OH}$, USA). The concentration of P was analyzed by ICP-OES (iCAP 7000 series, Thermo Fisher Scientific, Waltham, MA, USA). Calibration curves $(1,5,10,20$, and $50 \mathrm{mg} / \mathrm{L}$ ) were prepared using phosphorus standards (non-ferrous metals and electronic materials testing).

HPLC (Agilent 1200, Agilent Technologies, Santa Clara, CA, USA) was used to determine the content of organic acids. The HPLC column temperature was $30{ }^{\circ} \mathrm{C}$. The mobile phase included $2.5 \mathrm{wt} \%$ potassium dihydrogen phosphate $\left(\mathrm{KH}_{2} \mathrm{PO}_{4}\right)$ and methanol $\left(\mathrm{CH}_{3} \mathrm{OH}\right)$ in a ratio of 99:1. Phosphoric acid was used to adjust the $\mathrm{pH}$ of $\mathrm{KH}_{2} \mathrm{PO}_{4}$ to 2.8 at a rate of $1 \mathrm{~mL} / \mathrm{min}$. Oxalic acid and citric acid standard solutions were diluted to 2000, $1000,500,200,100,50$, and $0 \mathrm{mg} / \mathrm{L} \mathrm{[28].}$

$\mathrm{D} / \mathrm{Max}-2500$ X-ray diffraction (XRD, Rigaku Corporation, Tokyo, Japan) (Cu-K $\alpha$; $36 \mathrm{kV}$; $20 \mathrm{~mA}$; scanning from $5^{\circ}$ to $60^{\circ}$ at a speed of $4^{\circ} / \mathrm{sec}$ ) was used to analyze the precipitates. Before XRD analysis, the filtered thalli were dried in an oven, and then dry precipitated in a planetary ball mill (Mitr YXQM, Changsha Mitrcn Instrument Equipment Co., Ltd. (MITR), Changsha, China) for ball grinding and passing through a 100-mesh sieve [21]. MDI Jade 6.5 software was used to detect the results of XRD precipitation for phase identification. Scanning electron microscopy (SEM, S4800 Hitachi, Hitachi HighTechnologies Corporation, Tokyo, Japan) was used to study the surface morphology of the samples at $7 \mathrm{kv}$ accelerating voltage. Before the test, the sample was coated with a layer of gold in Hitachi E-1010 Sputter for one minute. The semi-quantitative analysis was performed by X-Max N 150 energy dispersive spectrometer (EDS, Oxford Instruments, Abingdon-on-Thames, UK) at $10 \mathrm{kv}$ accelerating voltage.

\subsection{Statistical Analysis}

The flask and soil incubation experiments were performed in triplicate. The means and standard deviations in each treatment were calculated and presented. The significant differences among the treatments were identified by Tukey's honestly significant difference test $(p<0.05)$ via one-way ANOVA. XRD and SEM analyses were carried out on a range of samples, and the typical results are presented in this study.

\section{Results}

\subsection{Fungal Biomass, $p H$, and P Content Released by A. niger in Flask Experiment}

The dry biomass of ANG in ANG + TCP treatment was significantly higher than in ANG + PG treatment (Figure 1A). After three days of incubation, the dry biomass in ANG + TCP treatment was $0.58 \mathrm{~g}$ (Figure 1A). The dry biomass of ANG in ANG + TCP treatment then increased to 0.70 and $0.71 \mathrm{~g}$ on days five and seven (Figure $1 \mathrm{~A})$. In ANG + PG treatment, the dry biomass of ANG was 0.34, 0.38, and $0.37 \mathrm{~g}$ after three, five, and seven days of incubation (Figure $1 \mathrm{~A}$ ).

The initial $\mathrm{pH}$ of the PVK medium was 6.5. In ANG + TCP treatment, the $\mathrm{pH}$ value was 3.02 on day three, significantly higher than the value of 2.52 in ANG + PG treatment (Figure 1B). However, the $\mathrm{pH}$ value had no significant difference between ANG + TCP and ANG + PG treatments on day five, i.e., 2.30 and 2.41 (Figure 1B). After seven days of incubation, the $\mathrm{pH}$ value in $\mathrm{ANG}+\mathrm{PG}$ treatment was 2.72, significantly higher than the value of 2.41 in ANG + TCP treatment (Figure 1B). 

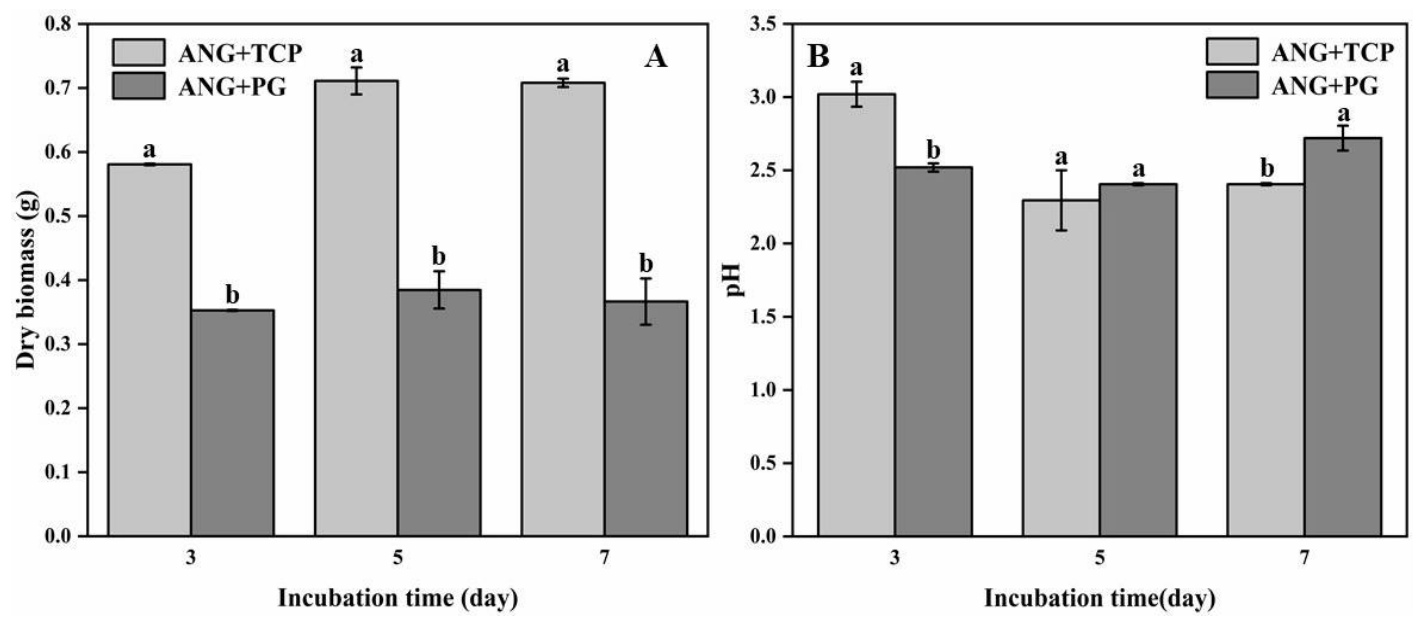

Figure 1. The dry biomass of $A$. niger (A) and $\mathrm{pH}$ value (B) between ANG + TCP and ANG + PG treatments during incubation $(3,5,7$ days). The different lower-case letters indicate a significant difference between the treatments $(p<0.05)$. The significant differences among the treatments were identified by the Tukey test $(p<0.05)$.

The P concentration in ANG + TCP treatment was $~ 10$ times higher than ANG + PG treatment during the incubation time (Figure 2A). In ANG + TCP treatment, the P concentration was $779.7,801.6$, and $1103.1 \mathrm{mg} / \mathrm{L}$ after three, five, and seven days of incubation (Figure 2A). In ANG + PG treatments, the P concentration was 66.5, 128.2, and $118.2 \mathrm{mg} / \mathrm{L}$ after three, five, and seven days of incubation (Figure 2A). The maximum P release ratio has a similar value $(\sim 55 \%)$ between ANG + TCP and ANG + PG treatments (Figure $2 \mathrm{~B})$. In ANG + TCP treatment, the release ratio of P continuously increased to $39.2 \%, 40.2 \%$, and $55.3 \%$ after three, five, and seven days of incubation (Figure 2B). In ANG + PG treatments, the release ratio of $\mathrm{P}$ was $27.3 \%, 52.1 \%$, and $48.1 \%$ after three, five, and seven days of incubation, and reached the maximum on day three (Figure 2B).
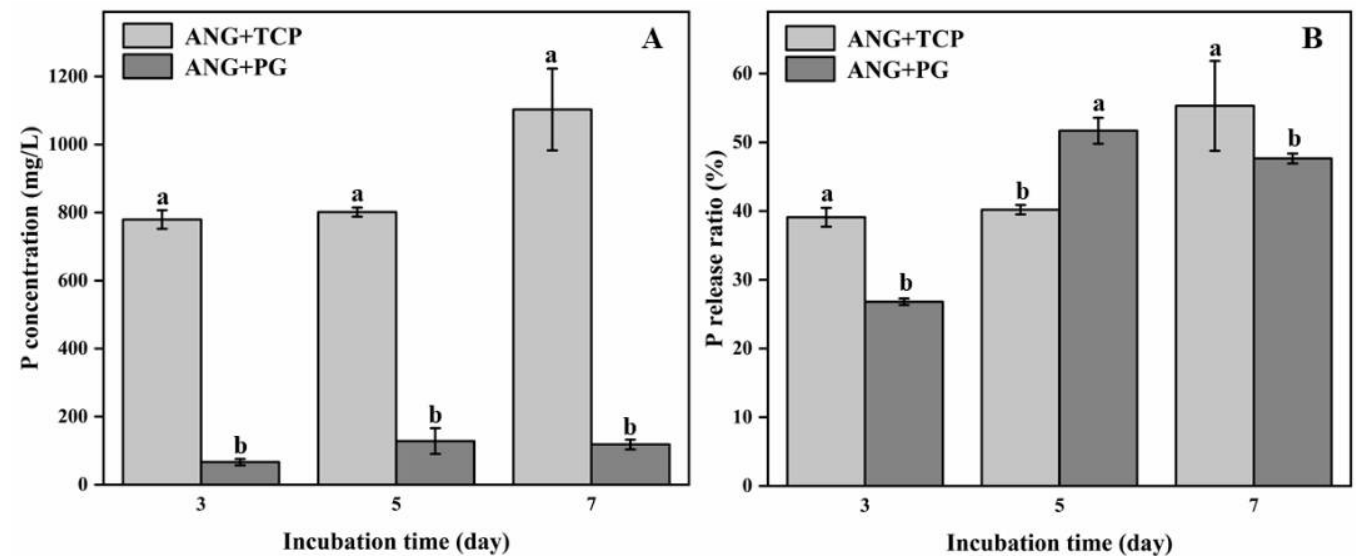

Figure 2. The $P$ concentration $(\mathbf{A})$ and $P$ release ratio $(\mathbf{B})$ between $A N G+T C P$ and $A N G+P G$ treatments during incubation $(3,5,7$ days). The different lower-case letters indicate a significant difference between the treatments $(p<0.05)$. The significant differences among the treatments were identified by the Tukey test $(p<0.05)$.

\subsection{Secretion of Organic Acids by A. niger in Flask Experiment}

Oxalic and citric acids were the two primary organic acids secreted by $A$. niger (Figure 3). The amount of oxalic acid secreted by A. niger in ANG + TCP treatment was significantly higher than in ANG + PG treatment during the whole incubation time (Figure 3A). In ANG + TCP treatment, the concentration of oxalic acid was $252.5 \mathrm{mg} / \mathrm{L}$ on day three and then decreased sharply to 65.2 and $74.5 \mathrm{mg} / \mathrm{L}$ on days five and seven (Figure 3A). In 
ANG + PG treatment, the oxalic acid secreted by A. niger was gradually increased from 11.9 to 14.5 to $23.9 \mathrm{mg} / \mathrm{L}$ after three, five, and seven days of incubation, respectively (Figure $3 \mathrm{~A}$ ). In contrast, the secretion of citric acid by A. niger in ANG + TCP treatment was significantly higher than ANG + PG treatment (Figure 3). In ANG + TCP treatment, the secretion of citric acid by $A$. niger decreased from 46.5 to 4.4 to $2.0 \mathrm{mg} / \mathrm{L}$ after three, five, and seven days of incubation, respectively (Figure 3B). In ANG + PG treatment, the secretion of citric acid was 11.6, 59.2, and $57.2 \mathrm{mg} / \mathrm{L}$ after three, five, and seven days of incubation, respectively (Figure 3B).
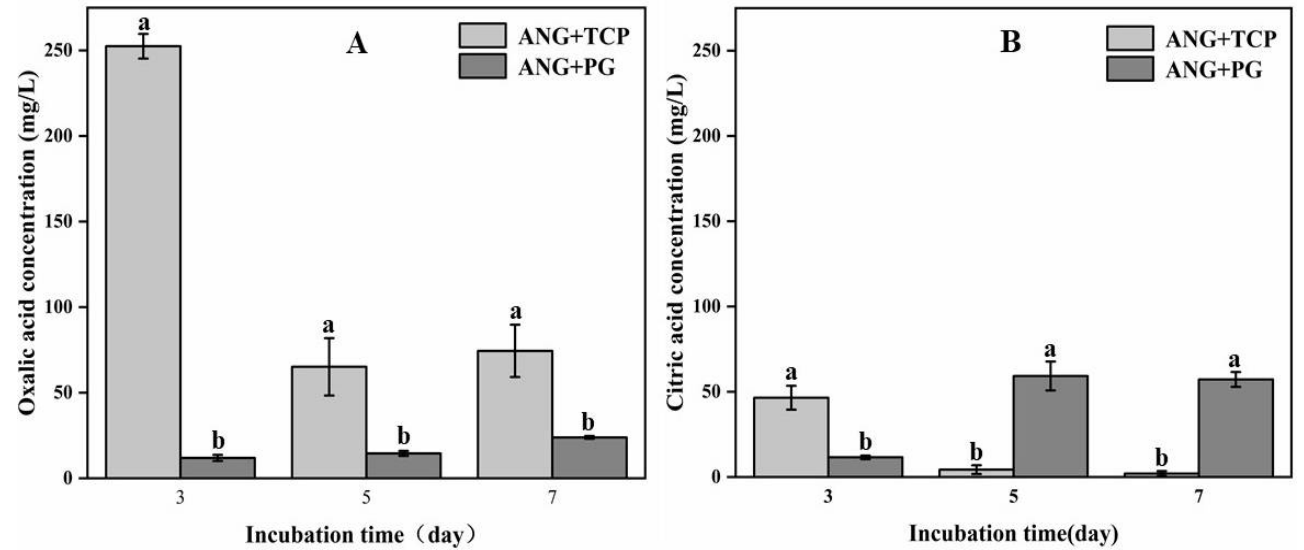

Figure 3. The secretion of oxalic acid (A) and citric acid (B) by between ANG + TCP and ANG + PG treatments during the incubation $(3,5,7$ days). The different lower-case letters indicate a significant difference between the treatments $(p<0.05)$. The significant differences among the treatments were identified by the Tukey test $(p<0.05)$.

\subsection{XRD Analysis}

XRD patterns show the minerals present in different treatments after seven days of incubation (Figure 4). In ANG + TCP treatment, the peaks at 29.4 and $31.0^{\circ}$ represented tricalcium phosphate $\left(\mathrm{Ca}_{3}\left(\mathrm{PO}_{4}\right)_{2}\right)$ (Figure 4$)$. The new peaks located at 14.3, 23.7 and $37.4^{\circ}$ in ANG + TCP treatment indicated the existence of calcium oxalate $\left(\mathrm{CaC}_{2} \mathrm{O}_{4}\right)$ (Figure 4). In $\mathrm{ANG}+\mathrm{PG}$ treatment, the $\mathrm{Ca}_{3}\left(\mathrm{PO}_{4}\right)_{2}$ peaks were detected at 25.8, 28.3 and $31.0^{\circ}$. The new $\mathrm{CaC}_{2} \mathrm{O}_{4}$ peaks were detected in $\mathrm{ANG}+\mathrm{PG}$ treatment at 14.3 and $23.7^{\circ}$. The new mineral calcium sulfate $\left(\mathrm{CaSO}_{4}\right)$ appeared in $\mathrm{ANG}+\mathrm{PG}$ treatment at a peak of $10.9^{\circ}$. In addition, the new lead oxalate $\left(\mathrm{PbC}_{2} \mathrm{O}_{4}\right)$ peak was observed at $32.4^{\circ}$ in $\mathrm{ANG}+\mathrm{PG}$ treatment.

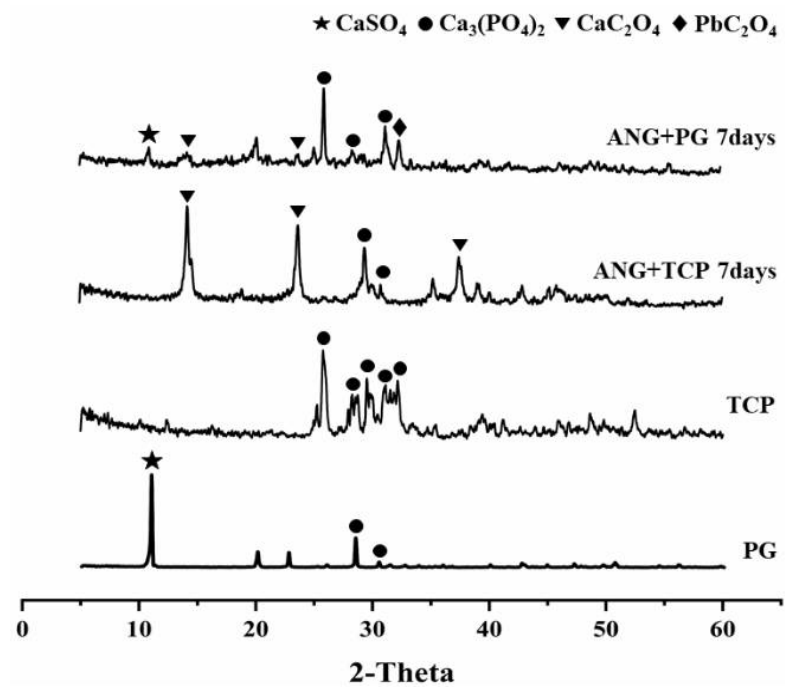

Figure 4. XRD patterns of the precipitation in ANG + TCP and ANG + PG treatments after 7 days of incubation. The patterns on the bottom are standard TCP and PG minerals. 


\subsection{Soil pH and Soil Soluble P Content}

The initial pH value in soil was 7.8 (Figure 5A). After one, two, and four weeks of incubation, the $\mathrm{pH}$ values in SS treatment were 7.8, 7.8, and 7.6, respectively (Figure 5A). $\mathrm{SS}+\mathrm{ANG}$ treatment decreased the $\mathrm{pH}$ value in the soil, and the $\mathrm{pH}$ values were 7.4, 7.4, 7.4 on weeks one, two, and four, respectively (Figure 5A). The pH value in SS+PG, SS+ANG+PG, and SS+PGF treatments decreased significantly (Figure 5A). After one and two weeks of incubation, the pH values in SS + PG treatment (6.9 and 6.9) were lower than SS + ANG + PG treatment (7.1 and 7.0) (Figure 5A). After four weeks of incubation, the $\mathrm{pH}$ value in SS + PG treatment (6.9) was higher than SS + ANG + PG treatment (6.6) (Figure 5A). The pH value in SS + PGF treatment decreased mostly (Figure 5A). In SS + PGF treatment, the $\mathrm{pH}$ values were $6.7,6.6$, and 6.6 after one, two, and four weeks of incubation, respectively (Figure $5 \mathrm{~A}$ ).
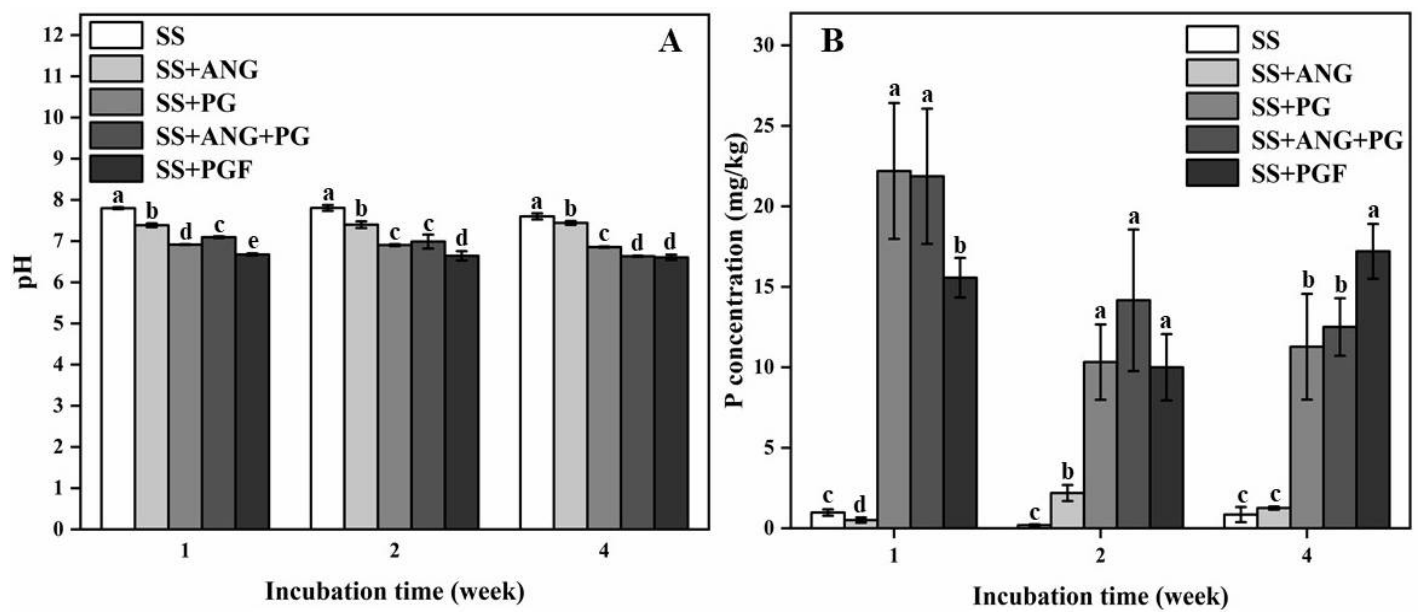

Figure 5. The $\mathrm{pH}$ value (A) and soluble $\mathrm{P}$ concentration $(\mathbf{B})$ in soil between $\mathrm{SS}, \mathrm{SS}+\mathrm{ANG}, \mathrm{SS}+\mathrm{PG}$, $\mathrm{SS}+\mathrm{ANG}+\mathrm{PG}$, and SS + PGF treatments during incubation $(1,2,4$ weeks). PGF, PG fertilizer. The different lower-case letters indicate a significant difference between the treatments $(p<0.05)$. The significant differences among the treatments were identified by the Tukey test $(p<0.05)$.

The initial water-soluble $P$ in soil was $0.9 \mathrm{mg} / \mathrm{kg}$. The P concentrations in SS + PG, $\mathrm{SS}+\mathrm{ANG}+\mathrm{PG}$, and SS + PGF treatments were significantly higher than SS and SS + ANG treatments (Figure $5 \mathrm{~B}$ ). In SS and SS + ANG treatments, the P concentrations were 1.0, $0.2,0.8$, and $2.2,0.5$, and $1.3 \mathrm{mg} / \mathrm{kg}$ after one, two, and four weeks of incubation, respectively (Figure 5B). After one week of incubation, the P concentration in SS + PG and $\mathrm{SS}+\mathrm{ANG}+\mathrm{PG}$ treatments were 22.2 and $21.9 \mathrm{mg} / \mathrm{kg}$, which was higher than SS + PGF treatment $(15.6 \mathrm{mg} / \mathrm{kg}$ ) (Figure $5 \mathrm{~B})$. After two weeks of incubation, the P concentration in SS + PG, SS + ANG + PG, and SS + PGF treatments showed no significant difference but decreased to $10.3,14.2$, and $10.0 \mathrm{mg} / \mathrm{kg}$, respectively (Figure $5 \mathrm{~B}$ ). After four weeks of incubation, the P concentrations in SS + PG and SS + ANG + PG treatments were significantly lower than SS + PGF treatment, which were $11.3,12.5$, and $17.2 \mathrm{mg} / \mathrm{kg}$, respectively (Figure 5B). Compared with PG, the inoculation of PGF increased 52.2\% water-soluble P content in soil after the incubation (Figure 5B). PG fertilizer can continuously increase the content of available P in soil compared with PG and PG + ANG treatment.

\subsection{SEM-EDS Analysis}

The SEM images show mineral and fungal morphology between ANG + TCP and ANG + PG treatments after seven days of incubation in the flask experiment (Figure 6). A. niger hypha can be observed in these two treatments (Figure 6). The mineral calcium oxalate, which has a prismatic crystal shape, was identified in ANG + TCP treatment (Figure 6A). In ANG + PG treatment, both tricalcium phosphate and calcium oxalate minerals were also observed (Figure 6B). 


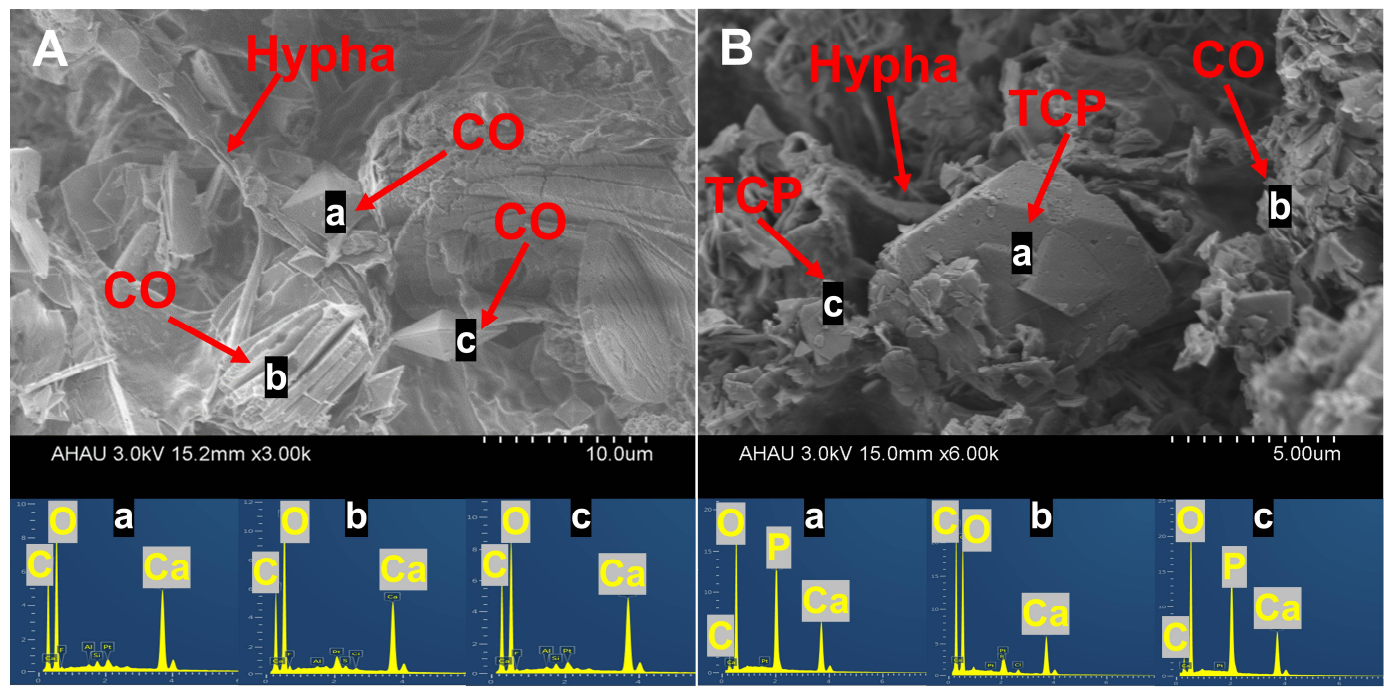

Figure 6. SEM-EDS imaging of the fungus and minerals in ANG + TCP (A), ANG + PG (B) treatments after 7 days of incubation. Points $a, b$, and c represent EDS analysis in ANG + TCP (A) and ANG + PG (B) treatments. $\mathrm{CO}$, calcium oxalate $\left(\mathrm{CaC}_{2} \mathrm{O}_{4}\right)$; TCP, tricalcium phosphate $\left(\mathrm{Ca}_{3}\left(\mathrm{PO}_{4}\right)_{2}\right)$.

The SEM images showed the morphology of minerals and fungi in PGF and SS + PGF treatment after four weeks of incubation in the soil incubation experiment (Figure 7). In PG fertilizer (PGF), both $A$. niger (hyphae and globular spores) and minerals (calcium oxalate and calcium sulfate) were observed (Figure 7A). In SS + PGF treatment, the morphology of soil block, crop straw, fungal hypha and spores were also clearly observed (Figure 7B).
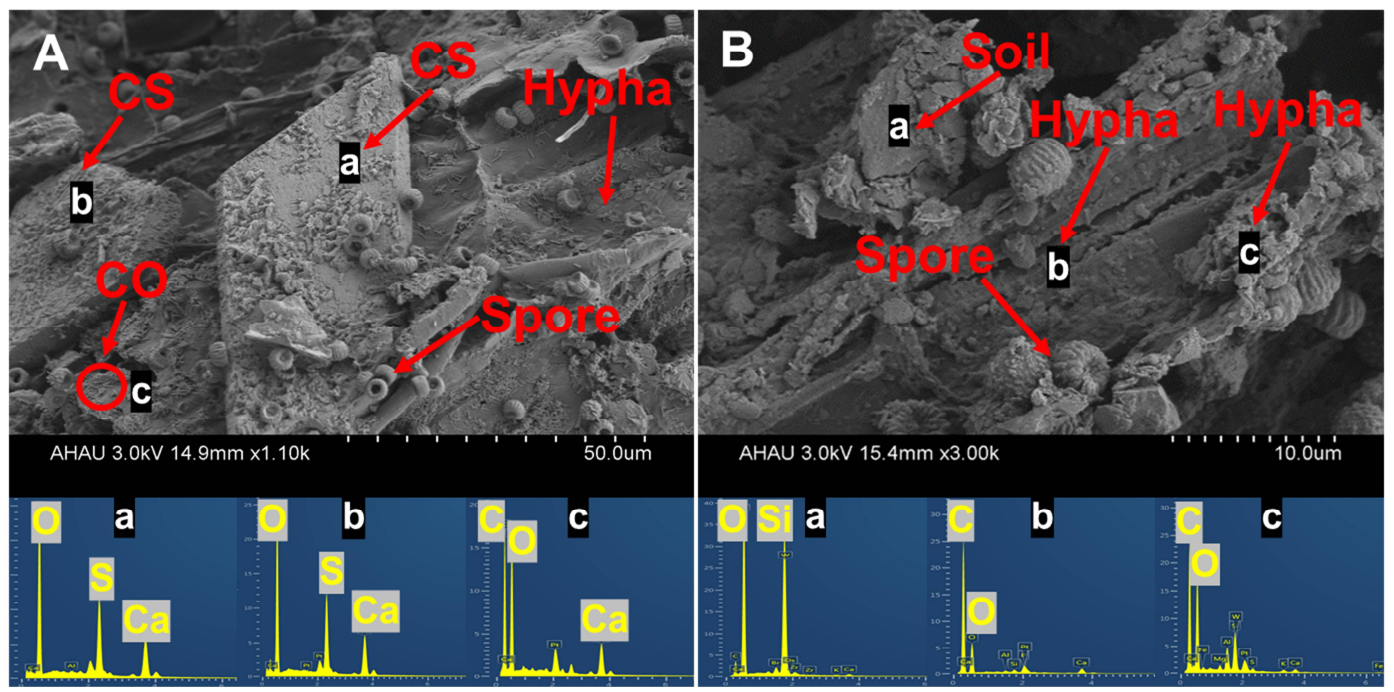

Figure 7. SEM-EDS imaging of the PGF (A) and SS + PGF (B) after 4 weeks of incubation. Points $a, b$, and $\mathrm{c}$ represent EDS analysis in PGF $(\mathbf{A})$ and SS + PGF $(\mathbf{B})$ treatments. CO, calcium oxalate $\left(\mathrm{CaC}_{2} \mathrm{O}_{4}\right)$; CS, calcium sulfate $\left(\mathrm{CaSO}_{4}\right)$.

\section{Discussion}

PG is a by-product of wet-process phosphoric acid production [7], with a low $\mathrm{pH}(2-4)$ and P content $(\sim 2 \%)$ [9]. Although PG has a low P content compared with TCP $(24.8 \mathrm{mg} / \mathrm{g}$ in PG vs. $200 \mathrm{mg} / \mathrm{g}$ in TCP) (Table S1), the P in PG is more easily released by A. niger (Figure 2). More importantly, the maximum P release ratio in PG is similar to TCP ( 55\%), but the time to achieve this ratio is shortened to five days (Figure 2B). On the one hand, PG is digested by strong chemical acid during phosphoric production and, hence, contains part of $P$ with high solubility, which is easy to release [32]. Our results indicated that the 
water-soluble P content in PG accounts for $14.7 \%$ of total P (Table S1). On the other hand, P in PG also exists in the form of eutectic $\mathrm{P}\left(\mathrm{CaHPO}_{4} \cdot \mathrm{H}_{2} \mathrm{O}\right.$ and $\left.\mathrm{CaSO}_{4} \cdot 2 \mathrm{H}_{2} \mathrm{O}\right)$, which is also easier to release than $\mathrm{Ca}_{3}\left(\mathrm{PO}_{4}\right)_{2}$ (the solubility of eutectic $\mathrm{P}$ is greater than $\mathrm{Ca}_{3}\left(\mathrm{PO}_{4}\right)_{2}$, i.e., $0.32 \mathrm{~g} / \mathrm{L}\left[\mathrm{CaHPO}_{4}\right]$ vs. $\left.0.02 \mathrm{~g} / \mathrm{L}\left[\mathrm{Ca}_{3}\left(\mathrm{PO}_{4}\right)_{2}\right]\right)$ [33-35].

Untreated PG also could contain toxic elements, such as heavy metal and fluorine, depending on the grade of the PO being processed [8]. These toxic elements could limit the growth of microbes and cause environmental pollution. However, A. niger still survives in PG treatment (Figure 1). Compared with other fungi (e.g., Penicillium oxalicum), A. niger has a higher tolerance to $\mathrm{Pb}(1500 \mathrm{mg} / \mathrm{L})$ and fluorine $(90 \mathrm{mg} / \mathrm{L})$ toxicity $[28,30]$. A. niger also maintains a high secretion ability of organic acids, especially in low $\mathrm{pH}(\sim 2)$ and high $\mathrm{Pb}$ toxicity (500-1500 mg/L) environments [28,30]. Our results also confirmed that A. niger can secrete oxalic and citric acids in PG treatment. This organic acid secreted by $A$. niger contributes to $\mathrm{P}$ release and $\mathrm{Pb}$ remediation. Although the amount of oxalic acid secreted by $A$. niger is less than citric acid $(20 \mathrm{vs} .60 \mathrm{mg} / \mathrm{L})$, the formed calcium oxalate in $\mathrm{ANG}+\mathrm{PG}$ treatment indicated that oxalic acid dominated the release of $\mathrm{P}$ from PG. With no $A$. niger treatment, both TCP and PG release $\mathrm{P}$ content is much lower than that with A. niger treatment (Table S2). In addition, the common mineral of lead oxalate was also detected in ANG + PG treatment (Figure 4), which also indicated that the release of $\mathrm{Pb}$ from PG can be easily immobilized by oxalic acid [36].

Organic acids secreted by $A$. niger can promote the release of $\mathrm{P}$ through chelation and acidification $[17,18]$, especially oxalic acid, which has a higher chelating ability and acidity constant, and usually dominates the dissolution of IPs [20]. Our XRD and SEM results also showed that oxalic acid dominated the dissolution of TCP and PG via the formation of calcium oxalate (Figures 4 and 6). The existence of $\mathrm{Ca}^{2+}$ can stimulate $A$. niger to secrete more oxalic acid [21]. However, the main component of calcium sulfate $\left(\mathrm{CaSO}_{4}\right)$ in $\mathrm{PG}$ has a lower solubility compared with TCP (less than $0.002 \mathrm{~g} / \mathrm{L}$ ) [37]. Hence, the secretion of oxalic acid by $A$. niger in TCP is higher than PG (Figure 3A). However, after five and seven days of incubation, oxalic acid in ANG + PG treatment showed an increasing trend (Figure 3). PG can stimulate $A$. niger to continuously increase the secretion of oxalic acid, which is important for the decomposition of IPs. Therefore, although TCP releases more $\mathrm{P}$, it does not promote P release efficiency compared with PG (Figure 2).

A. niger promoted the release of $\mathrm{P}$ in $\mathrm{PG}$ under liquid culture conditions. PG could only release $28 \mathrm{mg} / \mathrm{L} \mathrm{P}$ without $A$. niger, but it increased to $128 \mathrm{mg} / \mathrm{L}$ after adding $A$. niger (Table S2 and Figure 2). PG in soil can also rapidly increase soil P content $(22.2 \mathrm{mg} / \mathrm{kg})$, but released $P$ tended to be fixed (down to $10.3 \mathrm{mg} / \mathrm{kg}$ in the second week) (Figure $5 \mathrm{~B}$ ). Although PG has a higher P content in soil compared with PG fertilizer (PGF) at beginning of the soil incubation, PGF can continuously increase soil P content (Figure 5B). Unlike PG, the component of PGF is more complex, and the existence of straw can also adsorb part of $\mathrm{P}$. In addition, $A$. niger also has cellulase activity, which can promote the degradation of crop straw cellulose and thus increase the source of P in PGF [38,39]. Therefore, with the increased time of soil incubation, PGF shows a higher P content in soil (Figure 5B). In addition, $A$. niger has strong environmental resistance, and the mycelia extended by spores can be seen by SEM (Figure 7). The application of PGF reduces the $\mathrm{pH}$ of soil (Figure 5A), and can be used in saline-alkali land areas [40]. $\mathrm{Ca}^{2+}$ in PGF can replace $\mathrm{Na}^{+}$in soil colloid to achieve a desalination effect [41]. The use of PGF can also increase the content of some trace elements in soil, thus promoting the growth of plants [40]. Importantly, PGF application has been tested for the risk of lead-free contamination of soil. Although PG partly contended lead cations, the secretion of oxalic acid by A. niger can also immobilize $\mathrm{Pb}$, which has a low environmental risk.

\section{Conclusions}

PG is strongly acidic and could contain harmful elements such as $\mathrm{Pb}$ and $\mathrm{F}$, which carry environmental risk. A. niger can survive in a PG environment, not only promoting the release of phosphorus from PG, but also reducing environmental risk via the formation of 
lead oxalate. Compared with high phosphorus content phosphate (TCP), the phosphorus is easily and quickly released from PG by A. niger. Both PG and PG fertilizer can significantly increase the P concentration in soil without heavy metal pollution. However, the use of PG fertilizer can continuously improve the available phosphorus content in soil. In addition, the oxalic acid secreted by $A$. niger dominated the release of phosphorus from PG. The dissolution of PG in soil by $A$. niger in the future should be accompanied by increased oxalic acid secretion. In conclusion, the combination of $A$. niger and PG for PG fertilizer is a feasible pathway for the reuse of $\mathrm{PG}$, which can reduce the consumption of phosphate ore resources.

Supplementary Materials: The following supporting information can be downloaded at: https: / / www.mdpi.com/article/10.3390/agronomy12030646/s1, Table S1. The pH, total P concentration, water-soluble $\mathrm{P}$ concentration, and $\mathrm{Pb}$ concentration in PG. Table S2. The $\mathrm{pH}$ value and water-soluble P concentration between TCP and PG treatments (no ANG) during incubation (3, 5, 7 days). Table S3. The physical and chemical properties of Shajiang black soil.

Author Contributions: Conceptualization, D.T.; methodology, D.T.; validation, D.T., J.X., N.Z. and M.X.; formal analysis, D.T., J.X., N.Z., M.X. and X.L.; investigation, J.X., N.Z., M.X. and X.L.; resources, D.T., L.Z., S.D. and H.G.; data curation, D.T. and J.X.; writing-original draft preparation, D.T.; writing-review and editing, D.T. and J.X.; supervision, D.T., L.Z. and H.G.; funding acquisition, D.T. and H.G. All authors have read and agreed to the published version of the manuscript.

Funding: This research was funded by the Program at Department of Natural Resources of Anhui Province (NO. 2021-K-11), the National Natural Science Foundation of China (NO. 42007030 and NO. 41877099), and the Program at Anhui Agricultural University (NO. yj2019-20).

Institutional Review Board Statement: Not applicable.

Informed Consent Statement: Not applicable.

Data Availability Statement: Not applicable.

Acknowledgments: We thank Yang Xu from the Biotechnology Center of Anhui Agricultural University for technical support of SEM in this study.

Conflicts of Interest: The authors declare no conflict of interest.

\section{References}

1. Gadd, G.M. Geomycology: Biogeochemical transformations of rocks, minerals, metals and radionuclides by fungi, bioweathering and bioremediation. Mycol. Prog. 2007, 111, 3-49. [CrossRef]

2. Ruan, Y.Y.; He, D.S.; Chi, R. Review on beneficiation techniques and reagents used for phosphate ores. Minerals 2019, 9, 253. [CrossRef]

3. Cisse, L.; Mrabet, T. World Phosphate Production: Overview and Prospects. Phosphorus Res. Bull. 2012, 15, 21-25. [CrossRef]

4. Li, W.; Gao, H.; Luo, Y.; Gao, J. Status, trends and suggestions of phosphorus ore resources at home and abroad. China Min. Mag. 2015, 24, 6-10.

5. Karamesouti, M.; Gasparatos, D. Sustainable Management of Soil Phosphorus in a Changing World. In Adaptive Soil Management: From Theory to Practices; Rakshit, A., Abhilash, P., Singh, H., Ghosh, S., Eds.; Springer: Singapore, 2017; pp. 189-214, ISBN 978-981-10-3637-8.

6. Cordell, D.; Drangert, J.O.; White, S. The story of phosphorus: Global food security and food for thought. Global. Environ. Chang. 2009, 19, 292-305. [CrossRef]

7. Saadaoui, E.; Ghazel, N.; Ben Romdhane, C.; Massoudi, N. Phosphogypsum: Potential uses and problems-A review. Int. J. Environ. Stud. 2017, 74, 558-567. [CrossRef]

8. Tayibi, H.; Choura, M.; Lopez, F.A.; Alguacil, F.J; Lopez-Delgado, A. Environmental impact and management of phosphogypsum. J. Environ. Manag. 2009, 90, 2377-2386. [CrossRef]

9. Singh, M. Treating waste phosphogypsum for cement and plaster manufacture. Cem. Concr. Res. 2002, 32, 1033-1038. [CrossRef]

10. Canut, M.M.C.; Jacomino, V.M.F.; Bråtveit, K.; Gomes, A.M.; Yoshida, M.I. Microstructural analyses of phosphogypsum generated by Brazilian fertilizer industries. Mater. Charact. 2008, 59, 365-373. [CrossRef]

11. Tian, D.; Li, Z.; O'Connor, D.; Shen, Z.; Hou, D. The need to prioritize sustainable phosphate-based fertilizers. Soil. Use. Manag. 2020, 36, 351-354. [CrossRef] 
12. Al-Enazy, A.R.; Al-Oud, S.S.; Al-Barakah, F.N.; Usman, A.R. Role of microbial inoculation and industrial by-product phosphogypsum in growth and nutrient uptake of maize (Zea mays L.) grown in calcareous soil. J. Sci. Food. Agric. 2017, 97, 3665-3674. [CrossRef]

13. Rutherford, P.M.; Dudas, M.J.; Samek, R.A. Environmental impacts of phosphogypsum. Sci. Total Environ. 1994, 149, 2377-2386. [CrossRef]

14. Peng, H.; Fang, S.X.; Yang, W.Q.; Hai-Tao, H.E.; Zong, S.R. Microwave Weight Method for Rapid Determination of Total Phosphorus in Phosphogypsum. Guangzhou Chem. Ind. 2014, 42, 124-153.

15. Cao, J.-X. Study on existing form and distribution of the impurities in phosphogypsum. J. Guizhou Univ. Nat. Sci. Ed. 2009, 26, 95-99.

16. Shen, Z.; Tian, D.; Zhang, X.; Tang, L.; Su, M.; Zhang, L.; Li, Z.; Hu, S.; Hou, D. Mechanisms of biochar assisted immobilization of $\mathrm{Pb}^{2+}$ by bioapatite in aqueous solution. Chemosphere 2018, 190, 260-266. [CrossRef]

17. Kpomblekou, A.K.; Tabatabai, M.A. Effect of low-molecular weight organic acids on phosphorus release and phytoavailabilty of phosphorus in phosphate rocks added to soils. Agric. Ecosyst. Environ. 2003, 100, 275-284. [CrossRef]

18. Palmieri, F.; Estoppey, A.; House, G.L.; Lohberger, A.; Junier, P. Oxalic acid, a molecule at the crossroads of bacterial-fungal interactions-ScienceDirect. Adv. Appl. Microbiol. 2019, 106, 49-77.

19. Coutinho, F.P.; Felix, W.P.; Yano-Melo, A.M. Solubilization of phosphates in vitro by Aspergillus spp. and Penicillium spp. Ecol. Eng. 2012, 42, 85-89. [CrossRef]

20. Mendes, G.O.; Murta, H.M.; Valadares, R.V.; Silveira, W.B.; Silva, I.R.; Costa, M.D. Oxalic acid is more efficient than sulfuric acid for rock phosphate solubilization. Miner. Eng. 2020, 155, 106458. [CrossRef]

21. Tian, D.; Wang, L.; Hu, J.; Zhang, L.; Zhou, N.; Xia, J.; Xu, M.; Yusef, K.K.; Wang, S.; Li, Z.; et al. A study of P release from Fe-P and Ca-P via the organic acids secreted by Aspergillus niger. J. Microbiol. 2021, 59, 819-826. [CrossRef]

22. Da Silva, V.N.; de Souza Fernandes da Silva, L.E.; da Silva, A.J.N.; Stamford, N.P.; de Macedo, G.R. Solubility curve of rockpowder inoculated with microorganisms in the production of biofertilizers. Agric. Nat. Resour. 2017, 51, 142-147.

23. Tian, D.; Su, M.; Zou, X.; Zhang, L.; Li, Z. Influences of phosphate addition on fungal weathering of carbonate in the red soil from karst region. Sci. Total Environ. 2021, 755, 142570. [CrossRef]

24. Su, M.; Meng, L.Z.; Zhao, L.; Tang, Y.K.; Qiu, J.J.; Tian, D.; Li, Z. Phosphorus deficiency in soils with red color: Insights from the Interactions between minerals and microorganisms. Geoderma 2021, 404, 115311. [CrossRef]

25. Yin, Z.; Shi, F.; Jiang, H.; Roberts, D.P.; Chen, S.; Fan, B. Phosphate solubilization and promotion of maize growth by penicillium oxalicum P4 and Aspergillus niger P85 in a calcareous soil. Can. J. Microbiol. 2015, 61, 913-923. [CrossRef]

26. Li, Z.; Bai, T.; Dai, L.; Wang, F.; Tao, J.; Meng, S.; Hu, Y.; Wang, S.; Hu, S. A study of organic acid production in contrasts between two phosphate solubilizing fungi: Penicillium oxalicum and Aspergillus niger. Sci. Rep. 2016, 6, 25313. [CrossRef]

27. Li, X.; Luo, L.; Yang, J.; Li, B.; Yuan, H. Mechanisms for solubilization of various insoluble phosphates and activation of immobilized phosphates in different soils by an efficient and salinity-tolerant Aspergillus niger strain An2. Appl. Biochem. Biotechnol. 2015, 175, 2755-2768. [CrossRef]

28. Tian, D.; Jiang, Z.; Jiang, L.; Su, M.; Feng, Z.; Zhang, L.; Wang, S.; Li, Z.; Hu, S. A new insight into lead (II) tolerance of environmental fungi based on a study of Aspergillus niger and Penicillium oxalicum. Environ. Microbiol. 2019, 21, 471-479. [CrossRef]

29. Fomina, M.; Hillier, S.; Charnock, J.M.; Melville, K.; Alexander, I.J.; Gadd, G.M. Role of oxalic acid overexcretion in transformations of toxic metal minerals by Beauveria caledonica. Appl. Environ. Microbiol. 2005, 71, 371-381. [CrossRef]

30. Shao, X.; Hao, W.; Konhauser, K.O.; Gao, Y.; Tang, L.; Su, M.; Li, Z. The dissolution of fluorapatite by phosphate-solubilizing fungi: A balance between enhanced phosphorous supply and fluorine toxicity. Environ. Sci. Pollut. Res. 2021, 28, 69393-69400. [CrossRef] [PubMed]

31. Tian, D.; Lai, Z.; Zou, X.; Guo, C.; Tang, L.; Su, M.; Li, Z.; Hu., S. A contrast of lead immobilization via bioapatite under elevated $\mathrm{CO}_{2}$ between acidic and alkaline soils. Soil. Use Manag. 2018, 34, 542-544. [CrossRef]

32. Liang, H.; Zhang, P.; Jin, Z.; DePaoli, D. Rare-earth leaching from Florida phosphate rock in wet-process phosphoric acid production. Miner. Metall. Process. 2017, 34, 146-153. [CrossRef]

33. Gao, Y.X.; Ran, J.G.; Li, G.; Wang, F.H. Preparation of bioactive hydroxyapatite by a modifed method. Mater. Sci. Technol. 2004, 12, 156-159.

34. Yang, M. Solubility of phosphogypsum in pure water and lime solution. Adv. Mater. Res. 2011, 250, 131-135. [CrossRef]

35. Zhou, J.; Yang, L.; Lin, Q.; Cao, J.X. Analysis of phosphogypsum's physical and chemical properties and making of anhydrite cement from phosphogypsum. Appl. Mech. Mater. 2013, 275-277, 2131-2135. [CrossRef]

36. Li, Z.; Wang, F.; Bai, T.; Tao, J.; Guo, J.; Yang, M.; Wang, S.; Hu, S. Lead immobilization by geological fluorapatite and fungus Aspergillus niger. J. Hazard. Mater. 2016, 320, 386-392. [CrossRef]

37. Partridge, E.P.; White, A.H. The solubility of calcium sulfate from 0 to 200. J. Am. Chem. Soc. 2002, 51, 360-370. [CrossRef]

38. Tao, B.R.; Shao, L.P.; Ming-Ying, F.U.; Zhang, Y.; Zhou, X.S.; Zhu, L.Q. Effects of the Straw Concentrated Buried Return on Nitrogen and Phosphorus Leaching in Wheat Fields. Chin. J. Soil Sci. 2013, 44, 945-951.

39. Wang, X.; Wang, C.; Sui, J.; Liu, Z.; Li, Q.; Ji, C.; Song, X.; Hu, Y.; Wang, C.; Sa, R. Isolation and characterization of phosphofungi, and screening of their plant growth-promoting activities. Amb. Express. 2018, 8, 63. [CrossRef] 
40. Wu, H. Effects of soil amendment Phosphogypsum on physical and chemical properties of and wheat growth in coastal saline soil in Rudong, Jiangsu. Acta. Pedol. Sin. 2012, 49, 1262-1266.

41. Nayak, A.K.; Mishra, V.K.; Sharma, D.K.; Jha, S.K.; Singh, C.S.; Shahabuddin, M.; Shahid, M. Efficiency of Phosphogypsum and Mined Gypsum in Reclamation and Productivity of Rice-Wheat Cropping System in Sodic Soil. Commun. Soil Sci. Plant. Anal. 2013, 44, 909-921. [CrossRef] 